\title{
Purchase Intention of Counterfeit Products: The Role of Subjective Norm
}

\author{
Santi Budiman ${ }^{1} \&$ Tony Wijaya ${ }^{2}$ \\ ${ }^{1}$ IEU School of Business, Yogyakarta, Indonesia \\ ${ }^{2}$ Alumnus of Doctoral Program, Universitas Islam Indonesia, Indonesia \\ Correspondence: Santi Budiman, IEU School of Business, Yogyakarta, Indonesia. Tel: 62-27-455-1477. E-mail: \\ tonypascamm@yahoo.com
}

$\begin{array}{ll}\text { Received: September 13, } 2013 & \text { Accepted: November 25, } 2013 \quad \text { Online Published: March 24, } 2014 \\ \text { doi:10.5539/ijms.v6n2p145 } & \text { URL: http://dx.doi.org/10.5539/ijms.v6n2p145 }\end{array}$

\begin{abstract}
The purpose of the research is to test the purchase intention difference based on the subjective norm role and relationship of subjective norms. The research was done by testing the purchase intention difference when the subjective norm role was high and when the subjective norm was low. The sample in this research was the executive women that had knowledge about counterfeit bags. The respondents who were successful to be collected in the research were 86 executive women respondents in Yogyakarta-Indonesia. The data analysis in this research uses the difference testing helped by Analysis of Variance. The data analysis results show that there is the purchase intention difference based on the highness and the lowness of the subjective norm role of the consumers to use the counterfeit products. There are positive corellation between subjective norm and purchase intention. Consumers with the high subjective norm role have the low intention to buy and consumers with the low subjective norm role have the high intention to buy.
\end{abstract}

Keywords: purchase intention, subjective norm, counterfeit products

\section{Introduction}

Globally, the counterfeit product selling was until 299 billion dollar (Chakraborty, Allerd, Sukhdial, \& Bristol, 1997). The product counterfeiting impact seen from the business agent side were the loss of goodwill and consumers' trust toward company (Bamossy, 1985; Delener, 2000), the research and development cost that had been spent did not give additional value and the cost of formal legal matter became greater (Nash, 1989), and the decrease of the company profit of the legally branded products (Bloch, Bush, \& Campbell, 1993). The product counterfeiting impact from the consumers' point of view were the consumers did not have guarantee from the bought products or products did not have guarantee (Bamossy \& Scammon, 1985), the more developing counterfeiting with technology development made the consumers in the ambiguity in differentiating the original products from the fake products (Bush, Bloch, \& Dawson, 1989; Olsen \& Granzin, 1992; Nash, 1989; Wilkie \& Zaichkowsky, 1999).

The addition of the demand toward the counterfeit products have the great possibility caused by two main reasons, those are the cheaper of counterfeit products' prices compared with the original products and because the consumers can feel the economical benefits or have the perceived quality. Based on the previous introductory study, two main factors that have roles in shaping consumers' behavior toward counterfeit products are found, those are internal aspect in the form of attitude and external aspect in the form of environment encouragement such as the valid norm in society. Besides, consumers also see brands, labels, and design identity characters such as logogram, color, ornament, and accesories as additional value (Feitelberg, 2007; Ha \& Lennon, 2006; Kay, 1990; Babin, Darden, \& Griffin, 1994).

The product counterfeiting occurred because of several reasons, those were: the limitation of the original product availability in fulfilling the market demand; producers or retailers did not pay the taxes of the counterfeit products (Stewart, 2005); the prices of the counterfeit products was cheaper than the original ones, so it could bring the promising profits for the counterfeiter (Delener, 2000; Nill \& Shultz II, 1996; Lynch, 2002; Wijk, 2002); the fast technology development made all information could be accessed by all classes of society, so it inspired the counterfeiter to produce greatly the counterfeit products that were identical with the original 
products or there was the product example (Nill \& Shultz, 1996; Bush et al., 1989; Bamossy \& Scammon, 1985; Stewart, 2005); the business risk was very low, even without risk because promising the very cheap production and overhead cost, much cheaper compared with the production cost proportion of the original products because the used basic material was often not according to the standard; the cheap investment cost and did not need to spend research and development cost (Nill \& Shultz II, 1996; Delener, 2000; Stewart, 2005); had the very great potential market because the greatness of the consumers proportion with the middle to low income who were not able to buy the original products, besides the law infrastructure was still weak, signed by the government unconcern toward the products' counterfeiting (Bush et al., 1989; Delener, 2000; Wilkie \& Zaichkowsky, 1999; Lynch, 2002); the difficulty to compete with strong and popular products in consumers' eyes, so doing counterfeiting would ease the marketing because could join the original product popularity (Nill \& Shultz II, 1996).

Supporting the occurrence of the consumers' demand shift from the buying of the original products to the buying of the counterfeit products, those things strengthened the research results of the previous product counterfeiting that identified that the development of the counterfeit product industry was very fast, even the fastest developing industry in the world (Eisend \& Guler, 2006). It could be seen from the jumping up of the demand amount toward the counterfeit products from year to year that became the main cause of the fast development of the counterfeit products business.

The most popular counterfeit products in product counterfeiting market, among others were handbags (d' Astous \& Gargouri, 2001). Handbag products had become fashion statement that were counted as one of the product mode at that btime (Febriane \& Suwarna, 2011). Bag product brands that were often counterfeit were Louis Vuitton, Hermes, Channel, Gucci, Prada, Christian Dior, Chloe, Burberry (Ritson, 2007; Feitelberg, 2007). Data showed that fashion products (handbags) occupied the third position among 11 kinds of counterfeit products with $26 \%$ percentage in 2006, whereas kinds of counterfeit products were stated to increase to 200 million items, consisted of clothes products, accessories (handbags), and shoes occupied the highest position with 57\% percentage based on the data of European Union (European Commission, 2008).

Theoretically, individual behavior was influenced by external or environment factor that formed individual behavior directly or indirectly (Santrock, 2005). Lewin concept in formulating behavior function is the combination between organism (internal in the form of individual attitude) and environment aspect (external in the form of subjective norm role). Azjen (1991) called the external factor as the subjective norm that explained individual behavior. It was also confirmed by Oskamp (1991) that stated that attitude was influenced by evaluative process done by individual. Response would only occur if individual faced a stimulus that wanted the existence of individual reaction and the attitude of giving evaluation toward object (Shaw \& Constanzo, 1982). Oskamp (1991) explained that evaluative process was influenced by genetic and physiological factors, personal experience and reference group influence as parents' influence, social group or society group that influenced individual. That aspect furthermore was called normative belief by Ajzen (1991).

The subjective norm contains two main aspects those are reference norm hope, is the other side view that is regarded important by individual who suggests individual to present or not to present the certain behavior and individual willingness motivation to do or not to do the other side's opinion or mind that are regarded important that individual has to or does not have to behave. Several research results showed the subjective norm related with the buying behavior (Kalafatis, Pollard, East, \& Tsogas, 1999; Chiou, 1998). Beside the information based on price, consumers use intrinsic and extrinsic attributes when forming the opinion about the product quality. The research had shown that often not considering the attributes accurately, the consumers even abandoned the product attributes that in reality influenced the product quality significantly (Olson, Walker, \& Reukert, 1995).

The described phenomena are when information about quality as the evaluation source is low, consumers will follow the reference from outside. It will strengthen consumers' behavior. On the contrary when consumers do not need information about the product quality, consumers will not obey the suggestions of the external side. It will weaken consumers' behavior. Phenomena in the research is when consumers did not consider the attributes in the evaluation process of a product, so external factor in the form of subjective norm will become the factor with role in the evaluation process. So the subjective norm will weaken the intention to buy toward counterfeit products. On the contrary, when consumers consider the attributes in the evaluation process of a product, the external factor in the form of subjective norm will become the less considered factor by consumers in the evaluation process. So the subjective norm influences the highness or the lowness of intention to buy. The purpose of the research is to test the intention to buy difference of counterfeit products based on the highness or the lowness of subjective norm role of consumers when considering using counterfeit products. 
Research about product counterfeiting behavior, especially handbags, become interesting for researchers in Asian and European countries. Research about products' counterfeiting develops from different perspectives. Previous research results and model concluded something that was not always appropriate with condition and situation in Indonesia today. The problem encouraged the writer more to watch the intention to buy of counterfeit handbag product from external side. The consideration of the variables' choosing, among others was to watch more the empirical needs in the marketing field, beside the theoretical model that had existed previously. The previous researches by the other researchers had different locations, models, objects, subjects, times, variables, analyses, goals, and/or purposes, and generally done much abroad with different economical situation and culture from Indonesian condition. It was interesting to do this research because Indonesia occupied the 8th position of the highest product counterfeiting level countries in Asia in 2006 (United States Customs and Border Protection, 2007; European Commission, 2008). Subjective norm aspect that had a role in Indonesia tended to have the collective culture in the form of group needs or following group roles or environment factor outside individuals. The difference of subjective norm roles in collective culture and individuals caused the difference of subjective norm role in explaining the intention to buy of the counterfeit products. The done research had the purpose to test the difference of intention to buy of counterfeit products based on the highness and lowness of subjective norm role in consumers when considering counterfeit product

\subsection{Theoretical Framework and Hypothesis Development}

The subjective norm role toward intention by Fishbein and Ajzen (1975) used the term motivation to comply to describe this phenomenon, that was whether individuals obeyed others'view influencing his/her life or not. There are two main aspects in subjective norm, those are conviction toward hope, reference norm hope, are others' view that is regarded as important by individuals who suggest individuals to present or not to present certain behavior and individuals' willingness motivation to do or not to do others' opinion or ideas regarded as important that individuals must or must not behave. The higher individual's motivation to obey others' view or role in buying the organic foods, the higher the intention to buy the organic foods. Research result showed the existence of positive relation between subjective norm and intention to buy (Kalafatis, Pollard, East, \& Tsogas, 1999).

There are many controversies about whether normative belief concept is different from behavior (the belief about the consequences of behavior). These controversies come from the level difference between attitude and subjective norm that is not only the assumption of the reasoned action theory, but also of several other important theories. Examination toward intention model concept and Fishbein's action show that normative belief and behavior belief are very similar and really the same things. According to reasoned action theory, trust is a normative belief or belief about what is thought by group, meanwhile the last belief is the behavioral belief or belief about consequences that probably occur from reference group reaction toward individual behavior.

Several research results showed the subjective norm was related with the buying behavior (Kalafatis et al., 1999; Chiou, 1998). The research done today tries to explain the external aspect role in the form of subjective norm for the intention to buy of the counterfeit products, especially handbag products. Azjen (1991) explained that the normative belief, on the other side, related with the condition that individual or reference group was regarded important and agree or disagree with behavioral implementation. The strength of each normative belief is multiplied with the person's motivation to follow reference, and subjective norm estimation is gotten by adding the results of all references regarded as important and can be trusted by consumers. Quality factor is the basic attribute of consumers' evaluation toward products. Information about quality was the basic of consumers' attitude makers (Olson, 1997). Consumers need reference support when product attributes cannot be evaluated clearly. The belief on the information adopted from outside will strengthen the ethical consideration of consumers.

Oskamp (1991) proposed that attitude was influenced by evaluative process by individuals. Attitude is said as an evaluative response. Evaluative response means that the reaction form stated as attitude is based on evaluative process in individualks that concludes the stimulus in the form of good-bad values, positive-negative, pleasant-unpleasant, then crystalized as reaction potention toward attitude object. Responses will just occur if individuals are faced by a stimulus that wants individuals' reaction. So attitude gives evaluation toward object (Shaw \& Constanzo, 1982). Therefore, studying attitude also needs to study the factors that influence evaluative process, those are:

a. Genetical and physiological factors: As stated that attitude is studied, individual has certain characters that determine this attitude development direction. On the other hand, this physiological factor plays important role in forming attitude through physiological conditions, such as age or illness until he/she has to drink certain medicines. For example when he/she is still young, individual has negative attitude toward medicines, but after ill, has to drink 
certain medicines. The other example is when he/she is young, individual likes the loudly rock $\&$ roll music, but after old, prefers classical music.

b. Personal Experience: The other factor determining the attitude forming much is personal experience or person who is related with certain attitude. The direct personal experience gives the stronger influence than indirect experience. According to Oskamp, two specific aspects contribute in forming attitude. First is the event that gives strong impression toward individual (salient incident), that is traumatic event that drastically changes individual's life, such as the lost of extremities because of accident. Second is the object occurrence repeatedly (repeated exposure). The good example for this aspect is musical cassette advertisement. The more often a music is turned on in various media, the greater the person's possibility to buy it. The other example is the frequency highness of two people's meeting and cooperating; love is possible to grow between each other, or also known with Javanese proverb witing tresno jalaran soko kulino.

c. Parents' influence: Parents have great influence toward their children's life. Parents' attitude will become model role for their children. The event example to explain it is the musician parents will tend to bear children who also love music.

d. Peer group or society group gives influence toward individual. There is tendency that an individual tries to be same with his/her group friends (Ajzen called it normative belief). A bad boy/girl who schools and becomes friends with santri girls/boys may change not to be bad anymore.

e. Mass media is the media among the society. Various researches show that model in mass media build society's attitude that high thin body is the best for a woman. Additionally, food advertisement in media influences much society eating behavior. Therefore, mass media uses much by political party to influence society in general election.

External aspect of individual evaluation maker was summarized by Ajzen (1991) as normative belief. Subjective norm is individual belief toward norm, surrounding people, and individual motivation to follow the norm. there are two main aspects in subjective norm, those are conviction toward hope, reference norm hope, are others' view regarded as important by individual who suggests individual to present or not to present certain behavior and individual willingness motivation to do or not to do others' opinion or idea regarded as important that individual must or must not behave (Fisbein \& Ajzen, 1975). Ajzen (1991) explained that normative belief, on the other side, was related with condition that individual or reference group was regarded as important, and agreed or disagreed with behavior implementation. The strength of each normative belief is multiplied with the person motivation to follow reference, and subjective norm estimation is gotten by adding the results of all important references.

Attitude contribution variation toward counterfeit products on the intention to buy was determined by the belief change variation from subjective norm (De Matos, Ituassu and Rossi, 2007). The highness of the motivation to comply the suggestions from outside will strengthen positive attitude and it will stimulate the decrease of the intention to buy of the counterfeit products. On the contrary, the lowness of the belief to follow suggestions from outside will decrease the consumers' belief to respond the counterfeit products. It will increase the tendency of buying the counterfeit products. The statement indirectly shows the existence of the difference of the intention to buy level of the counterfeit products based on the subjective norm consideration. Thus, it can be hypothesized as follows:

Ha: There is the difference of the intention to buy of the counterfeit products based on the subjective norm aspect.

\section{Method}

\subsection{Kind of Research}

Kind of research in this research was survey research. This research used primary data that were collected using survey through questionnaire about subjective norm and intention to buy of counterfeit products. Primary data was gotten by giving questionnaire directly on the samples who were met. Questionnaire was adopted from De Matos et al. research (2007) and used interval scale.

\subsection{Research Subjects}

Subjects of this research were the consumers who used the bag products in DIY. The sample withdrawal method was purposive sampling, that was the consumers with profession as executive women and able to identify counterfeit bag products. The difference testing (on group) such as Analysis of Variance, t-test, MANOVA, etc. needed approximately 30 samples per cell/group for $80 \%$ strength (Wijaya, 2012), so the samples needed were 
30 samples per group at the minimum rate.

\subsection{Variables Operational Definition}

\subsubsection{Variable of Intention to Buy of Counterfeit Products (NB)}

The intention to buy of the counterfeit products is the tendency of individual willingness to buy and use the counterfeit products. The instrument used refers to the measurement tool developed by De Matos et al (2007). The variable score data of the intention to buy of the counterfeit products are gotten from the computation results of the answer scores of the scale items filled by respondents in research scale statements.

\subsubsection{Subjective Norm Variable (NS)}

Subjective norm is individual belief to obey directions or suggestions of surrounding people to join in buying or using counterfeit products. Instrument used refers to the measurement tool developed by De Matos et al (2007). The score data of the subjective norm variable are gotten from the computation results of the answer scores of the scale items filled by the respondents on the research scale statements.

\subsection{Research Instrument Test}

Validity test is done to know whether an instrument of measurement tool has performed its measurement function. According to Sekaran (2003) validity showed the exactness and accuracy of the measurement tool in doing its measurement function. To know the data consistency and accuracy collected from instrument use, validity test is used by using correlation of product moment pearson. Based on validity test, it is known that item correlation value for intention to buy variable ranges from $0.62-0.85$ and subjective norm variable ranges from $0.47-0.63$ above significant $(<0.000)$ that means all items on the scale are valid (Wijaya, 2012).

Reliability test is related with the problem of the trust existence toward instrument. An instrument can have high trust level (consistent) if the result of instrument test shows persistent result. Thus, instrument reliability problem is related with result accuracy problem. Reliability test is done to know stability level of a measurement tool. In this research, reliability test is done by using the approach of internal consistency reliability that uses Cronbach Alpha. Based on reliability test, it is known that alpha value for intention to buy variable is 0.78 and subjective norm is 0.82. A factor was stated reliable if Alpha coefficient was more than 0.7 (Sekaran, 2003).

\section{Data Analysis Method}

Data analysis in this research uses Analysis of Variance in identifying intention to buy difference based on subjective norm. The framework of this research is as follows:

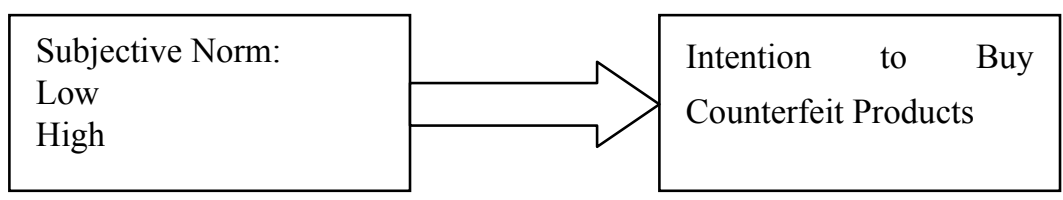

Figure 1. Research framework

\section{Results}

Respondents in this research were the female workers or female executives aged 24-45 years old, with education level from Diploma 3 until Strata 2 and lived in DIY. The analyzed respondents were 86 and divided into two groups, those were respondents with low and high subjective norms.

Based on data analysis, it is descriptively known that intention to buy variable of low subjective norm respondents is 4.3884 in average and of high subjective norm respondents is 2.7674 in average. It means that the high subjective norm consumers have low intention to buy while low subjective norm consumers have high intention to buy. Descriptive analysis results are presented in the following table:

Table 1. Descriptive statistic of purchase intention

\begin{tabular}{llll}
\hline Variable & N & Mean & Standard Deviation \\
\cline { 2 - 5 } High Subjective Norm & 43 & 2.7674 & 0.39444 \\
Low Subjective Norm & 43 & 4.3884 & 0.33961 \\
\hline
\end{tabular}

Source : Processed of Primary Data, 2013. 
The analysis of intention to buy difference based on subjective norm uses difference test. Hypothesis testing with calculation-F significance is $0.000<0.05$ that means there is intention to buy difference based on the highness or lowness of subjective norm. Thus, hypothesis (Ha) that states the difference existence of intention to buy of counterfeit products based on subjective norm aspect is accepted. The data analysis output results using Analysis of Variance are as follows:

Table 2. Correlation and analysis of variance

\begin{tabular}{lll}
\hline & & sig \\
\hline Subjective norm*Purchase Intention & $\mathrm{r}=0.421$ & 0.000 \\
& $\mathrm{~F}=417.020$ & 0.000 \\
\hline
\end{tabular}

The research results are consistent with the suggested recommendation by De Matos et al. (2007) that states the existence of norm aspect role forms intention to buy. Consumers who obey positive norms will have intention to avoid counterfeit products because regarded inappropriate with the value in society. In accordance with Oskamp's explanation (1991), evaluative process is influenced by reference group factors such as parents, social group, or society group who influences individual. Consumers who obey friends or the person who understands bag products will form cognitive pattern that the original products have more value rather than counterfeit products, and have responsibility to pay attention to the ethical values.

\section{Discussion}

Subjective norm has a role to explain intention to buy. It is in accordance with behavior concept revealed by Fishbein and Ajzen (1975) in reasoned action theory. Normative belief and subjective norm, that is individual belief toward norm, surrounding people, and individual motivation to follow norm. subjective norm involves two main aspects those are reference norm hope, is others' view regarded as important by individual who suggests individual to present or not to present certain behavior and individual willingness motivation to do or not to do others' opinion or idea regarded as important that individual must or must not behave. Fishbein and Ajzen (1975) stated that focus in understanding individual behavior was the intention to do predicted behavior. Intention is determined by attitude toward behavior and subjective norm of behavior. Thus, attitude is individual internal factor and subjective norm is individual perception toward pressure from environment or individual's external. In the other words, subjective norm is situational factor that influences individual to do or not to do a behavior. Ajzen (1991) stated that attitude and subjective norm interacted to each other in determining behavior intention. It is in accordance with Lewin's concept that behavior is the formulation of environment and organism interaction. The stronger the environment aspect role is, the stronger the tendency to behave, so does the response of organism or individual in considering environment aspect.

Oskamp (1991) suggested that attitudes are influenced by the evaluative process performed by an individual, while the evaluative process is influenced by genetic factors and physiological, personal experience and the influence of reference groups such as parental influence, social groups or community groups that give effect to the individual. This result should be followed when studying attitudes also by studying the factors that influence the evaluative process because the attitude is an evaluative response. Mann (1969) stated that subjective norms are social norms that contain a moral concept that plays a role in the formation of individual attitudes towards something. Some research indicates subjective norms related to purchase behavior (Chiou, 1998; Kalafatis et al., 1999; Sampson, 2009).

Indonesian society who tends to be collective pays attention toward norms that should to be followed. Collective culture tends to pay attention toward group's needs or norms in group, so group demand is crystallized in individual decision making. The importance of following rules or suggestions from group causes the highness and lowness of the intention to purchase especially ethical nuanced counterfeit products. The relation of attitude and behavior is determined much by certain situational factors. Norms, roles, values, culture, and ethical aspects are dependence condition that can strengthen or weaken the relation between attitude and behavior.

Based on data analysis, it can be concluded that there is intention to buy difference in consumers with low and high subjective norms. Consumers with high subjective norm role have low intention to buy while consumers with low subjective norm role have high intention to buy. Practically, to reduce the intention to buy of counterfeit products, education for consumers about ethical aspect, and benefit value and original products' quality is needed. Education will increase understanding toward original products so able to press counterfeit products' buying. Understanding of ethical aspects of product use through good communication is also needed. The further 
research can consider the effects of the highness or lowness of subjective norm in predicting consumers' behavior in product consumptions, especially counterfeit products. Another weakness of the study is the sample problem. Future studies need to develop a broader sample of the results of this study support a robust. Data collection method uses questionnaire, so the further research can use interview. So the picture of behavior is broader and deeper.

\section{References}

Ajzen, I. (1991). The Theory of Planned Behaviour. Organisational Behaviour and Human Decision Processes, 50, 179-211. http://dx.doi.org/10.1016/0749-5978(91)90020-T

Babin, B., Darden, W., \& Griffin, M. (1994). Work and/or Fun: Measuring Hedonic and Utilitarian Shopping Value. Journal of Consumer Research, 20, 644-656. http://dx.doi.org/10.1086/209376

Bamossy, G., \& Scammon, D. L. (1985). Product Counterfeiting: Consumers and Manufacturers Beware. In Elizabeth C. Hirschman \& Moris B. Holbrook (Eds.), Advances in Consumer Research (Vol. 12, pp. 334-339). Association for Consumer Research.

Bloch, P. H., Bush, R. F., \& Campbell, L. (1993). Consumer Accomplices in Product Counterfeiting: A Demand-Side Investigation. Journal of Consumer Marketing, 10(4), 27-36. http://dx.doi.org/10.1108/07363769310047374

Chakraborty, G., Allred, A., Sukhdial, A. S., \& Bristol, T. (1997). Use of Negative Cues to Reduce Demand for Counterfeit Products. Advances in Consumer Research, 24, 345-349.

Chiou, J. S. (1998). The Effects of Attitude, Subjective norm, and Perceived Behavioral Control on Consumers' Purchase Intentions: The Moderating Effects of Product Knowledge and Attention to Social Comparison Information. Proceedings of the National Science Council, 9, 298-308.

d'Astous, A., \& Gargouri, E. (2001). Consumer Evaluations of Brand Imitations. European Journal of Marketing, 35(6), 153-167. http://dx.doi.org/10.1108/03090560110363391

de Matos, C. A., Ituassu, C. T., \& Rossi, C. A. V. (2007). Consumer Attitudes toward Counterfeits: A Review And Extension. Journal of Consumer Marketing, 24(1), 36-47. http://dx.doi.org/10.1108/07363760710720975

Delener, N. (2000). International Counterfeit Marketing: Success without Risk. Review of Business, 21(6), $16-20$.

Eisend, M., \& Schuchert-Güler, P. (2006). Explaining Counterfeit Purchases: A Review and Preview. Academy of Marketing Science Review.

European Commission. (2008). Customs Seizures of Counterfeit Goods. Retrieved July 31, 2008, from http://europa.eu/rapid/pressReleasesAction.do? Reference $=$ MEMO/08/310

Febriane, S., \& Suwarna, B. (2011). Hasrat dalam Kemewahan Tas. Kompas, hlm. 1.

Feitelberg, R. (2007). Schumer Touts Plan to Fight Design Theft, Women's Wear Daily. Retrived August 13, 2008, from http://www.wwd.com

Fishbein, M., \& Ajzen, I. (1975). Belief, Attitude, Intention, and Behavior: An Introduction to Theory of Research. Reading, MA: Addison-Wesley.

Ha, S., \& Lennon, S. J. (2006). Purchase Intent for Fashion Counterfeit Products: Ethical Ideologies, Ethical Judgments, and Perceived Risks. Clothing and Textiles Research Journal, 24(4), 297-315. http://dx.doi.org/10.1177/0887302X06293068

Kalafatis, S. P., Pollard, M., East, R., \& Tsogas, M. H. (1999). Green Marketing and Ajzen's Theory of Planned Behaviour: A Cross-Market Examination. Journal of Consumer Marketing, 16(5), 441-460. http://dx.doi.org/10.1108/07363769910289550

Kay, H. (1990). Fake's Progress. Management Today, July, 54-58.

Lynch, S. (2002). Commercial Counterfeiting. Paper prepared for Trade Inspections Conference.

Mann, L. (1969). Social Psychology. Sydney: John Wiley \& Sons Australia PTY, Ltd.

Nash, T. (1989). Only Imitation? The rising Cost of Counterfeiting. Director, 5.

Nill, A., \& Shultz, C. J. II. (1996). The Scourge of Global Counterfeiting. Business Horizons, 39(6), 37-43. http://dx.doi.org/10.1016/S0007-6813(96)90035-X 
Olsen, J. E., \& Granzin, K. L. (1992). Gaining Retailers' Assistance in Fighting Counterfeiting: Concep-tualization and Empirical Test of a Helping Model. Journal of Retailing, 68(2), 90-111.

Olson, E. R., Walker, O. C., \& Ruekert, R. W. (1995). Organizing for Effective New Product Development: The Moderating Role of Product Inovativeness. Journal of Marketing, 59(1), 48-62. http://dx.doi.org/10.2307/1252014

Oskamp, S. (1991). Attitudes and opinions. Englewood Cliffs, NJ: Prentice Hall.

Ritson, M. (2007). Fakes Can Genuinely Aid Luxury Brands. Marketing, 7(25), 21-23.

Sampson, L. K. (2009). Consumer Analysis of Purchasing Behavior for Green Apparel. Thesis, North Carolina State University.

Santrock, J. W. (2005). Psychology. New York: McGrawHill.

Sekaran, U. (2003). Research Methods for Bussiness. New York: John Wiley \& Sons.

Stewart, C. (2005). Brand piracy: A Victimless Crime? Americans Want Stricter Counterfeiting and Piracy Laws. $\begin{array}{llll}\text { Retrieved June } & \text { 8, 2008, } & \text { from }\end{array}$ http://www.nam.org/s_nam/bin.asp?CID=201820\&DID=233395\&DOC=FILE.PDF

United States Customs and Border Protection. (2007). US Customs Service IPR Seizures. Retrieved from http://www.cbp.gov/inkhandler/cgov/import/commercial_enforcement/ipr/seizure/trading/fy06_ipr_stat.ctt/f y06_ipr_stat.pd

Wijaya, T. (2012). Research Methods for Economic and Business: Theory and Practice. Yogyakarta: Graha Ilmu.

Wijk, J. V. (2002). Dealing with Piracy: Intellectual Asset Management in Music and Software. European Management Journal, 20(6), 689-698.

Wilkie, R., \& Zaichkowsky, J. L. (1999). Brand Imitation and its Effects on Innovation, Competition, and Brand Equity. Business Horizon, Nov-Dec. http://dx.doi.org/10.1016/S0007-6813(99)80033-0

\section{Copyrights}

Copyright for this article is retained by the author(s), with first publication rights granted to the journal.

This is an open-access article distributed under the terms and conditions of the Creative Commons Attribution license (http://creativecommons.org/licenses/by/3.0/). 